\section{Author Correction: Innervation of thermogenic adipose tissue via a calsyntenin 3ß-S100baxis}

https://doi.org/10.1038/s41586-020-03161-z

Correction to: Nature https://doi.org/10.1038/s41586-019-1156-9

Published online 01 May 2019

Check for updates

Xing Zeng, Mengchen Ye, Jon M. Resch, Mark P. Jedrychowski, Bo Hu, Bradford B. Lowell, David D. Ginty \& Bruce M. Spiegelman

We have noted several issues associated with the statistical analysis and the Methods reported in this Article. First, we used unpaired $t$-tests for individual time points in experiments involving time courses, which may be problematic for multiple comparisons. We have now re-analysed all time course data using repeated-measures two-way analysis of variance (ANOVA) tests. The repeated-measures two-way ANOVAs did not assume sphericity, but instead a general (that is, unstructured) covariance structure. Analyses were conducted in GraphPad Prism v.8.0.0 for Windows (GraphPad Software, https://www.graphpad.com). On the basis of those analyses, we now report $P$ values for factor one $\left(P_{\text {genotype }}\right)$, factor two $\left(P_{\text {time }}\right)$, and the interaction between them $\left(P_{\text {genotype } x \text { time }}\right)$. The results are as follows: Fig. $3 \mathrm{c}: P_{\text {genotype }}=0.0022, P_{\text {time }}<0.0001, P_{\text {genotype } x \text { time }}$ $<0.0001$; Fig. 3d: $P_{\text {genotype }}<0.0001, P_{\text {time }}<0.0001, P_{\text {genotype } \times \text { time }}=0.001$; Fig. 3f: $P_{\text {genotype }}=0.0042, P_{\text {time }}<0.0001, P_{\text {genotype } \times \text { time }}=0.4912$. Note that the $P_{\text {genotype } x \text { time }}$ value suggests that time does not have a statistically significant influence on the difference between wild-type (WT) and knockout (KO) mice. Fig. 4c: $P_{\text {genotype }}=0.0006, P_{\text {time }}<0.0001, P_{\text {genotype } \times \text { time }}<$ $0.0001 ;$ Fig. $4 \mathrm{~d}: P_{\text {genotype }}=0.0031, P_{\text {time }}<0.0001, P_{\text {genotype } x \text { time }}<0.0001$; Fig. 4f: $P_{\text {genotype }}=0.028, P_{\text {time }}<0.0001, P_{\text {genotype } \times \text { time }}=0.0442$. Fig. 5f: $P_{\text {genotype }}=0.0134, P_{\text {time }}<0.0001, P_{\text {genotype } x \text { time }}<0.0001 ;$ Fig. $5 \mathrm{~g}: P=0.0068$ (hM3Dq+CNO versus hM3Dq+saline), $P=0.0099$ (hM3Dq + CNO versus mCherry + CNO); Fig. $5 \mathrm{~h}: P_{\text {genotype }}=0.0237, P_{\text {time }}=0.359, P_{\text {genotype } \times \text { time }}=$
0.8961 . The analysis was performed only on mice receiving an injection of clozapine- $N$-oxide (CNO). These results suggest that the changes in body temperature after $\mathrm{CNO}$ injection are statistically different with respect to genotype but not to time, and time does not have a significant effect on the difference between wild-type and knockout mice. Fig. 5i: $P_{\text {genotype }}=0.0036, P_{\text {time }}=0.0063, P_{\text {genotype } \times \text { time }}=0.5371$. Note the $P_{\text {genotype } x \text { time }}$ value suggests that time does not have a significant influence on the difference between wild-type and transgenic mice. Fig. 6e: $P_{\text {genotype }}=0.0055, P_{\text {time }}<0.0001, P_{\text {genotype } x \text { time }}<0.0001$. Note that $P_{\text {genotype }}$ reached statistical significance in all cases and therefore our original conclusions remain valid.

Second, for Fig. 6f, we have re-analysed the data using a one-factor ANOVA, adjusting pairwise comparisons with Tukey's method; this updates our original two-sample $t$-tests. For TH staining: WT versus $S 10 O b$ KO $P=0.0017$ (instead of $P=0.003$ ); WT versus Clstn $3 b$ Tg; $S 10 O b$ KO $P=0.0005$ (instead of $P=0.002$ ); and $S 100 b$ KO versus Clstn $3 b$ Tg;S1OOb KO $P=0.674$ (instead of $P=0.28$ ). For TUBB3 staining: WT versus $S 100 b$ KO $P<0.0001$ (instead of $P=0.0003$ ); WT versus Clstn $3 b$ $\mathrm{Tg} ; \mathrm{S} 100 b \mathrm{KO} P<0.0001$ (instead of $P=0.0003$ ); $S 10 O b \mathrm{KO}$ versus $C l s t n 3 b$ Tg; $S 10 O b$ KO $P=0.838$ (instead of $P=0.53$ ). Note that our original conclusion-that TH and TUBB3 staining in $S 10 O b$-knockout mice is not significantly different from staining in Clstn $3 b$-transgenic and $S 10 O b$-knockout mice-remains valid.

Third, in Fig. 1b, we compared expression levels of $C l s t n 3 b$ between different tissues from the same mouse. A paired $t$-test may be more appropriate here than the unpaired $t$-test used in the original Article. We have therefore re-analysed the data using a paired $t$-test and the results are as follows: BAT versus iWAT $P=0.0059$ (instead of $P=0.0006$ ); $P B A T$ versus eWAT $P=0.0097$ (instead of $P=0.0004$ ); iWAT versus eWAT $P=0.1951$ (instead of $P=0.08$ ). Note that our original conclusion - that the expression of $C l s t n 3 b$ is significantly higher in BAT than in WAT depots-remains valid.

Fourth, when calculating the standard error, we applied Bessel's correction by dividing the standard deviation by ' $(n-1)$ ' but not by ' $n$ '. We then found out that this correction has already been performed by the standard deviation formula of Microsoft Excel. Hence, all error bars in figures are larger than the correct values by a factor of $\sqrt{\frac{n}{n-1}}$. We have corrected the error bars accordingly. This mistake does not affect the calculation of any $P$ value or any conclusion based on statistical analysis.

Finally, for each replicate in Fig. 5a, we used cells pooled from 5 mice, and measured basal and noradrenaline-stimulated respiration. Altogether, a total of 20 wild-type mice and 20 knockout mice were used for replicates. Figures 1-4 of this Amendment show the corrected figure panels alongside the incorrect, published panels from Figs. 3-6 of the original Article, for transparency to readers. The original Article has been corrected online. 
Original Fig. 3c, $d, f$
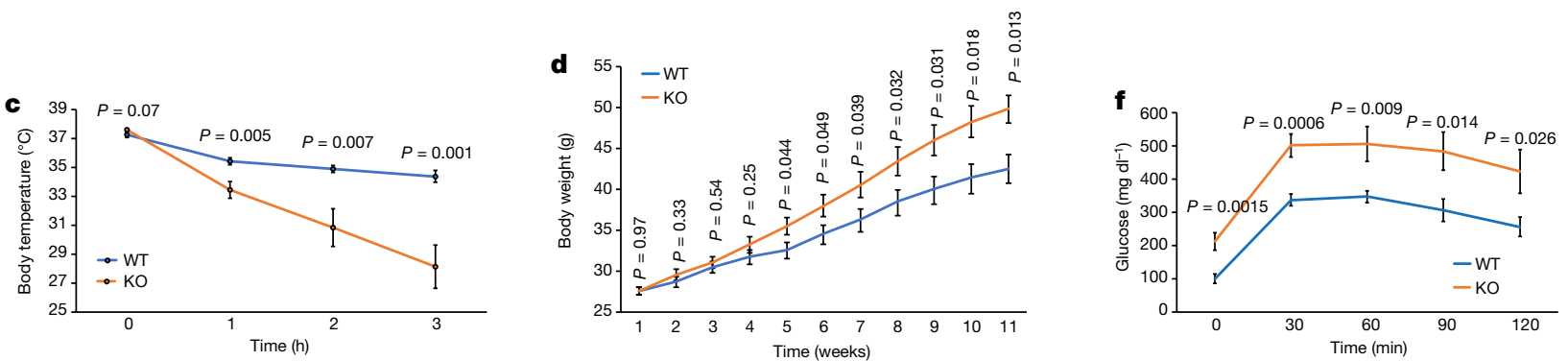

Corrected Fig. 3c, d, $f$
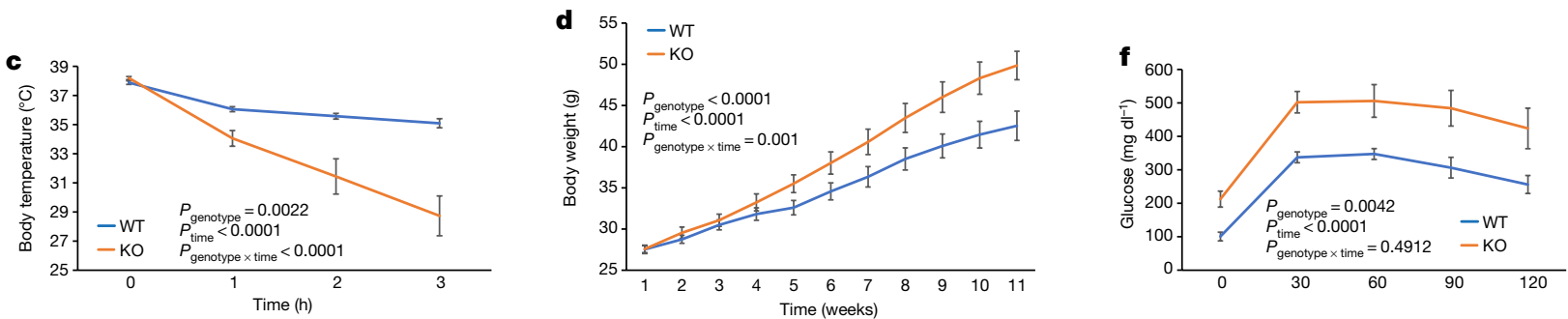

Fig. 1 | This figure displays the corrected and the uncorrected published Fig. 3c, d, f of the original Article.

Original Fig. 4c, d, $f$
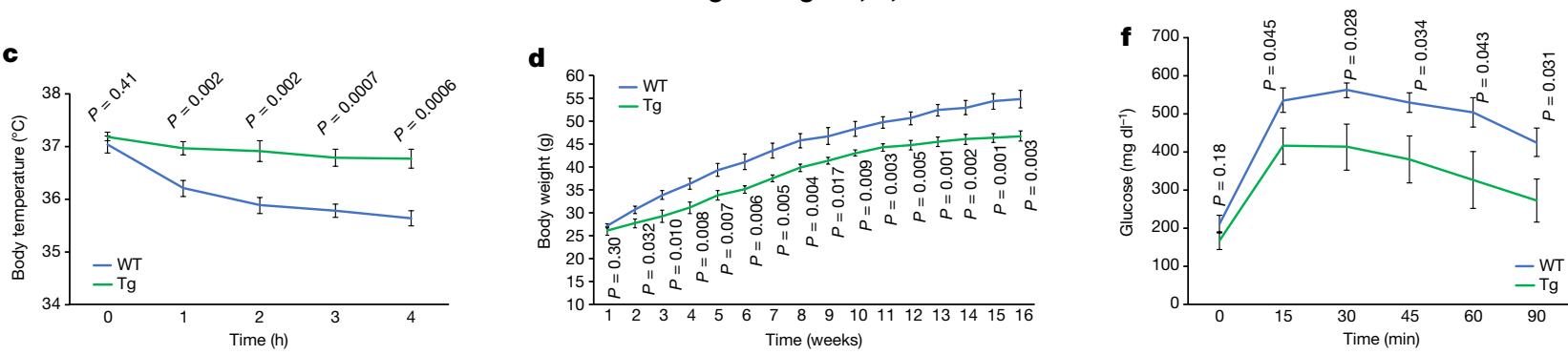

Corrected Fig. 4c, d, $f$
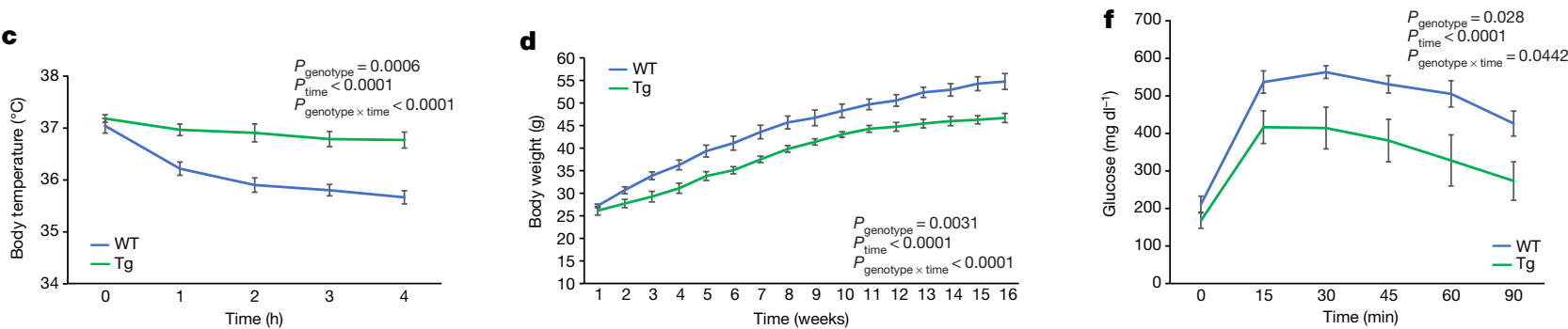

Fig. 2 | This figure displays the corrected and the uncorrected published Fig. 4c, d, f of the original Article. 
Original Fig. 5f-i
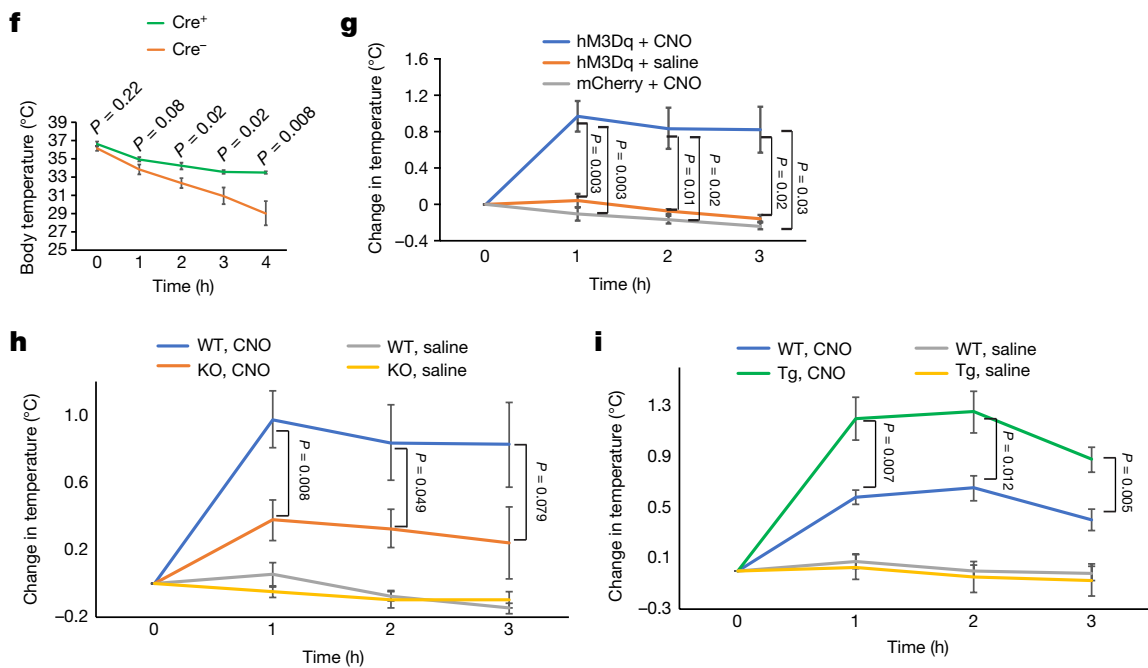

Corrected Fig. 5f-i
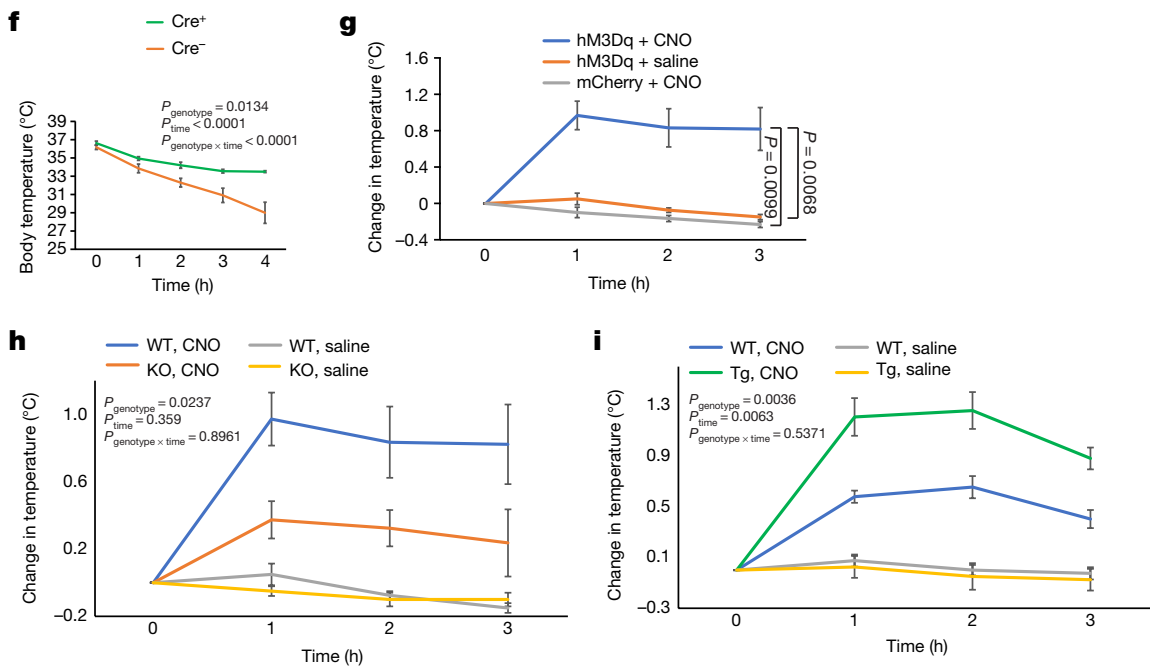

Fig. 3 | This figure displays the corrected and the uncorrected published Fig. $5 f-i$ of the original Article.

Original Fig. 6e

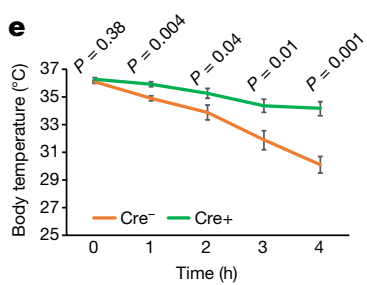

Corrected Fig. 6 e

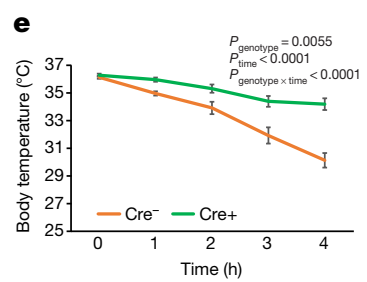

Fig. 4 | This figure displays the corrected and the uncorrected published Fig. 6e of the original Article. 